\title{
A Ópera A B ERT A \\ A força do destino, de Nélida Piñon, e $E$ la nave va, de Federico Fellini
}

Leonardo Francisco Soares

UFMG

\begin{abstract}
RESU M O
Análise dos processos contemporâneos de produção mimética e de representação, a partir do romance $A$ força do destino e do filme E la nave va, com vistas a articular os conceitos e noções de imagem-cristal, espetacularização, dialogismo, polifonia e desreferencialização como operadores constitutivos dessas narrativas.
\end{abstract}

PALAVRAS - CHAVE

literatura contemporânea, representação, cinema ópera

$\mathbf{E}_{\mathrm{m}}$ um capítulo intitulado "A ópera”, do romance Dom Casmurro, Machado de Assis apresenta, na fala da personagem Marcolini, um tenor decadente e já "sem voz", a seguinte afirmação:

- A vida é uma ópera e uma grande ópera. O tenor e o barítono lutam pelo soprano, em presença do baixo e dos comprimários, quando não são o soprano e o contralto que lutam pelo tenor, em presença do mesmo baixo e dos mesmos comprimários. Há coros numerosos, muitos bailados, e a orquestração é excelente... ${ }^{1}$

Na cosmogonia de Marcolini, Deus é o poeta que escreveu um libreto de ópera, do qual abre mão, por entender que tal criação não é própria de sua eternidade. Satanás é o jovem músico de grande futuro, mas que, ao tramar uma rebelião, é expulso do conservatório do céu. Ao sair, Satanás leva consigo, para o inferno, o manuscrito abandonado. Com o objetivo de provar o seu valor, ele compõe a partitura e a leva ao "Padre Eterno", que se recusa a ouvir o trabalho. Todavia, após as intermináveis súplicas de Satanás, Deus, "cansado e cheio de misericórdia", consente que a ópera seja encenada, mas fora do céu. Assim, Ele cria um teatro especial - o nosso planeta e inventa uma companhia inteira, com todas as partes, protagonistas e coadjuvantes.

Se a metafísica é excessiva, não importa: o texto de Machado de Assis ajudanos a pensar o que seria a natureza da ópera. Nessa opera mundi apresentada na fala de Marcolini, Machado lerá o espetáculo operístico como um (des)equilíbrio entre a ordem, clareza e harmonia do libreto de Deus, e a desordem, exuberância e desmedida da música de Satanás - uma perspectiva muito próxima à encontrada em Nietzsche, por exemplo. Para o filósofo alemão, um dos efeitos específicos da tragédia musical,

${ }^{1}$ Assis. Obra completa, v.1, p.815. 
germe do discurso operístico, seria a "aliança fraterna de Apolo e Dioniso, o ápice das finalidades artísticas apolíneas, assim como das dionisíacas”. ${ }^{2}$ À ordem, à medida apolínea, vem juntar-se a desordem, a desmedida dionisíaca, em uma confluência de sentidos e possibilidades narrativas. ${ }^{3}$ Dessa maneira, podemos entrever tanto na alegoria machadiana quanto na leitura de Nietzsche a consciência da pluralidade e da multiplicidade de vozes e universos presentes na ópera, embora Machado volte um olhar bem menos maniqueísta para as figuras de Deus/Apolo e de Satanás/Dioniso.

Por trás de toda sua irônica cosmogonia metafísica, Machado de Assis traz um interessante aspecto do discurso operístico: a possibilidade de transformação do cotidiano em espetáculo, o momento em que realidade e ficção se unem, eliminando a distinção entre espectador e espetáculo. Aspecto esse que será exaustivamente desenvolvido em A força do destino e em E la nave va - tanto o romance de Nélida Piñon quanto o filme de Federico Fellini parecem trazer o mote: "A vida é uma ópera e uma grande ópera”. Quem conhece o romance e o filme, entretanto, poderá desconfiar da aproximação que aqui começa a ser proposta. Todavia, ela ilumina nossa leitura, que se alimenta de misteriosas semelhanças, combinações e intertextualidades.

Em E la nave va (1983), Federico Fellini narra a viagem do transatlântico Glória $\mathrm{N}$, encarregado de lançar em alto mar as cinzas de uma diva da ópera (Edmea Tetua), no limiar da Primeira Guerra Mundial. A primeira seqüência é uma citação, na qual simula-se e representa-se a história do próprio cinema, começando como um filme antigo, em preto e branco, que aos poucos vai ganhando fluência, movimento e cor. Esse conjunto admirável de fotogramas apresenta a evolução do discurso cinematográfico: temos, primeiramente, o cinema primitivo - a fixidez da objetiva —, imagens "sujas" registram a chegada dos passageiros ao cais; não há ainda a combinação dos planos, o primeiro ruído é o de uma velha câmara de projeção. Depois desses planos, autônomos e auto-suficientes, da multidão no cais emerge uma espécie de caleidoscópio do universo felliniano, com seus clowns e suas matronas, enquanto a câmara inicia os primeiros movimentos de eixo. A seguir surgem "ruídos realistas", os do navio, para aparecer em seguida, como nos filmes mudos, o uso do gráfico, os intertítulos, a primeira cartela: "Perguntam o que está acontecendo. Quem sabe?". Aos poucos, as imagens vão ganhando uma certa linearidade. Finalmente, ao som do piano, com a chegada do carro fúnebre, o espectador é informado a respeito das cinzas de Edmea Tetua, o motivo da viagem; nesse momento, a cor aparece lentamente, assim como as vozes, os diálogos, os amplos movimentos de câmara e a primeira ópera: La forza del destino. O navio segue sobre o mar de plástico, enquanto os passageiros cantam: "Sigamos sobre as vagas da alegria e do pesar. A rota mais romântica do navio que vai."

A primeira ópera a irromper em E la nave va, La forza del destino, irá marcar a viagem do Gloria N. O tema musical do "Destino", toda a composição de abertura e outras passagens da ópera de Giuseppe Verdi, com libreto de Francisco Maria Piave e

\footnotetext{
${ }^{2}$ Nietzsche. Obras incompletas, p.42.

${ }^{3}$ Esse olhar sobre a ópera, tomando-a como "cena dupla", não é privilégio de Machado de Assis e Nietzsche. Muitos autores, como, por exemplo, Bertolt Brecht e Theodor Adorno, verão o discurso operístico como espaço da confluência de linguagens distintas, a falada e a musical, o elo entre prazer e irrealidade. Cf. Clement. A ópera ou a derrota das mulheres, p.30-5.
} 
Antonio Ghislanzoni, serão ouvidos, ao longo do filme de Federico Fellini, ao lado de trechos de outras óperas de Verdi, assim como obras de compositores como Rossini, Bellini e Tchaikovski, citados e transcriados pelo olhar do cineasta italiano. Entretanto, a ópera não é apenas uma referência presente na trilha sonora ou no enredo do filme, ao contrário, enredada em uma teia intersemiótica, a narrativa fílmica de Federico Fellini toma a ópera, com seu texto musical e teatral, como parte constitutiva de sua produção e de sua textura. Assim, E la nave va desenvolve-se como uma grande ópera montada sob o aparato técnico do cinema.

La forza del destino, o melodrama do amor impossível de Álvaro e Leonora, que funciona como "abertura" de E la nave va, é também a entrada principal do romance A força do destino (1977), de Nélida Piñon:

Unicamente por minhas mãos ingressariam ambos na língua portuguesa [Álvaro e Leonora], que é, como expliquei a Álvaro, um feudo forte e lírico ao mesmo tempo. Um barco que até hoje singra generoso o Atlântico, ora consolando Portugal, ora perturbando o Brasil. E porque esta língua tem vocação marítima, entende bem os impropérios do vento, mais que qualquer outra se deixa levar pelos sentimentos. ${ }^{4}$

Movida por sua paixão pela ópera e tomando como embarcação para a sua viagem a língua portuguesa, a escritora Nélida Piñon aliou a sua arte à do compositor Giuseppe Verdi, compondo o romance A força do destino, uma paródia da grande ópera, escrita em 1862 e encenada a primeira vez, no mesmo ano, em São Petersburgo. Por sua vez, a ópera de Verdi já era a reescrita de um outro texto, a peça de Angel Saavedra, o Duque de Rivas, inauguradora do Movimento Romântico Espanhol, Dom Álvaro o la fuerza del sino (1835). Como no teatro catóptrico, uma narrativa espelha outra, que, por sua vez, contém muitas outras, apontando para inúmeros universos textuais. Nélida Piñon assume a absorção e a reelaboração de outros textos, e, como um jogo de caixas chinesas, a representação, em A força do destino, faz-se representação dentro de uma representação, em uma "construção em abismo" que nos leva a refletir sobre a natureza do fenômeno artístico, desvelando suas potencialidades narrativas.

O universo do espetáculo (spetaculum) com seus jogos de máscaras e espelhos (speculuns) irá instalar-se no interior das narrativas de Federico Fellini e de Nélida Piñon. Os dois autores chamam para o diálogo, além da ópera, uma variedade de outros discursos. No caso de E la nave va, temos, por exemplo, o teatro, a pintura, o circo, o melodrama romântico, a comédia muda, a avant-garde cinematográfica, o drama histórico, entre outros discursos. Já em A força do destino serão apropriados o folhetim romântico do século XIX, os seriados cinematográficos, a fotonovela e a telenovela, o romance policial, as chanchadas, dentre outros. Aqui, tomaremos um denominador comum, o discurso operístico, as várias vozes presentes na ópera, cujo germe encontra-se há mais de 2500 anos, na Grécia.

Em E la nave va, Federico Fellini volta o seu olhar, nem um pouco complacente, para um grupo de personagens ligadas à cena lírica reunidas em torno de um evento comum: a última viagem da diva Edmea Tetua (Janet Suzman), cujas cinzas serão lançadas nas águas da Ilha de Erimo, onde nasceu a cantora. De Ildebranda Cuffari

${ }^{4}$ Piñon. A força do destino, p.12. 
(Barbara Jefford), uma das rivais de Edmea Tetua, ao grotesco tenor Aureliano Fuciletto (Victor Poletti), o cortejo fúnebre reúne uma série de personas caras ao universo felliniano. O desempenho dos atores aparece como símbolo do afetamento teatral levado ao cume, assim como o cenário, a maquiagem e o figurino nos remetem ao espetáculo operístico com todos os seus artifícios. Por outro lado, a ópera adentra o plano da ação pelo viés do bastidor: "em Fellini, esta ou aquela imagem é subjetiva, mental, lembrança ou fantasma, mas não se organiza como espetáculo sem se tornar objetiva, sem entrar nos bastidores, na 'realidade do espetáculo, daqueles que o fazem, vivem dele, se arranjam com ele". ${ }^{5}$

Nesse sentido, em E la nave va, por exemplo, a seqüência do concurso de canto oferecido aos carvoeiros do Gloria N é emblemática, pois nesse momento as personagens de Federico Fellini tornam-se espectadoras complacentes dos papéis que elas próprias representam. ${ }^{6}$ Em um incessante trocar de papéis, os passageiros-cantores vão à casa de máquinas para ver o proletariado, que, de espetáculo, passa a espectador do concurso de canto imposto aos de cima. É o universo do voyeur, o exibicionismo, o prazer de ser visto levado ao extremo da futilidade e do exagero. A primeira imagem dessa seqüência apresenta os carvoeiros trabalhando, vistos de cima, em um plano médio. Em seguida, um corte, os passageiros-cantores chegam para ver a casa das máquinas e se alojam em uma espécie de "camarote": "O palco é a casa de máquinas, décor da ópera moderna, suprema irrisão espacial aos textos líricos que os cantores cantam". ${ }^{7}$ Os carvoeiros percebem a presença dos passageiros-cantores, param de trabalhar e pedem para ouvir a Sra. Cuffari cantar: "Cante para nos consolar". A afetada diva, Ildebranda Cuffari, hesita e o tenor Aureliano Fuciletto toma a frente e começa a cantar. De repente, todos os passageiros-cantores passam a travar um duelo de vozes e de cantos sob o olhar maravilhado dos carvoeiros.

Nesse momento, os passageiros-cantores são filmados de baixo para cima, de forma grotesca, com suas bocas escancaradas ocupando todo o espaço da tela, em um exagero que beira a monstruosidade. Para o grotesco, a boca é a parte mais marcante do rosto: "A boca domina. $\mathrm{O}$ rosto grotesco se resume afinal em uma boca escancarada, e todo o resto só serve para emoldurar essa boca, esse abismo corporal escancarado e devorador." Através da ambivalência do "cânon grotesco", Federico Fellini associa as imagens heterogêneas dos passageiros-cantores e dos funcionários da casa de máquinas, aproximando-as e permitindo o exercício de um outro olhar, de uma outra ordem. O navio, imagem-cristal por excelência, encontra-se cindido em duas faces: a face límpida, que é o navio de cima, onde se encontram as classes dominantes nomes célebres da cena lírica, aristocratas - e a face opaca, que é o navio por baixo, onde estão as classes dominadas - funcionários do navio, o proletariado. Na seqüência do concurso de canto, paradigmática de seu olhar, Federico Fellini faz girar os circuitos, levando às últimas conseqüências as tensões entre alto/baixo, interior/exterior, espectador/espetáculo, atual/virtual.

\footnotetext{
${ }^{5}$ Deleuze. A imagem-tempo, p.17.

${ }^{6}$ Deleuze. A imagem-tempo, p.15.

${ }^{7}$ Costa. Federico Fellini, p.78.

${ }^{8}$ BAKHTin. A cultura popular na Idade Média e no Renascimento: o contexto de Rabelais, p.277.
} 
(...) a face límpida atualiza uma espécie de teatro ou de dramaturgia que se apodera dos próprios passageiros, ao passo que o virtual entra na face opaca, e se atualiza por sua vez nos acertos de contas entre foguistas, na perversidade diabólica de um chefe de tripulação, na monomania de um capitão, na secreta vingança de negros rebelados. É o circuito de duas imagens virtuais que não cessam de se atualizar, e não cessam de se relançar. ${ }^{9}$

Assim como o navio, as personagens também encontram-se sulcadas. Aristocratas, burgueses, proletários e refugiados estão no mesmo navio, porém uma clara divisão delineia-se, como na cena do jantar, na qual os refugiados sérvios assistem pelas vidraças - como por uma vitrine ou por um aquário - ao exibicionismo da classe dominante.

Os ricos comem devagar, não temem nenhuma falta, nenhuma carência. Ao mastigar, eles zelam, sobretudo, pela sua aparência, talvez por se saberem filmados. Do lado de fora, os refugiados sérvios vigiam, desejam, devoram com os olhos as mesas fartas. O vidro/vitrine, imagem especular, funciona como médium, fenômeno limiar. Nesse momento, fica nítido o conflito entre as classes, pois: "a vitrine é a maneira mais cínica através da qual o luxo se deixa entrever, assinalando, ao mesmo tempo, seu preço e seu dono. Exibicionismo que significa também modo radical de separação". ${ }^{10}$ Sob o olhar sôfrego e desejante dos refugiados, a única saída para os aristocratas e burgueses é fechar as cortinas, isolando-se em seu mundo de frivolidade. O olhar do outro, refugiado/estrangeiro, mesmo para o exibicionismo burguês, torna-se insuportável. Fellini parece dialogar de forma sublime com o poema "Les yeux des pouvres" de Charles Baudelaire: "Ces gens-là me sont insupportables avec leurs yeux ouverts comme des portes cochères! Ne pourriez-vous pas prier le maître du café de les eloigner d'ici." 11

Por outro lado, E la nave va traz momentos nos quais aristocratas e proletários, sem o limite das vitrines, integram-se, como na seqüência em que os passageiroscantores, seduzidos pela beleza e sensualidade da dança e da música cigana, são levados a misturar-se aos antes excluídos refugiados sérvios. Nessa cena, o convés do navio transforma-se em uma verdadeira "praça pública carnavalesca", espaço no qual ocorre a eliminação provisória das relações hierárquicas, imperando o livre contato familiar entre os homens:

Na literatura carnavalizada, a praça pública, como lugar da ação do enredo, torna-se biplanar e ambivalente: é como se através da praça pública real transparecesse a praça pública carnavalesca do livre contato familiar e das cenas de coroações e destronamentos públicos. Outros lugares (evidentemente motivados em termos de enredo e realidade), se é que podem ser lugares de encontro e contato de pessoas heterogêneas — ruas, tavernas, estradas, banhos públicos, convés de navios, etc. - recebem nova interpretação público- carnavalesca. ${ }^{12}$

É interessante notarmos que, no início da seqüência, alguns passageiros-cantores ainda tentam rotular a dança cigana, classificá-la, enquadrá-la em consonância a um

\footnotetext{
${ }^{9}$ Deleuze. A imagem-tempo, p.93.

${ }^{10}$ Hardman. Trem fantasma, p.15.

${ }^{11}$ Baudelaire. Petits poèmes en prose, p.88.

${ }^{12}$ Bakhtin. Problemas da poética de Dostoievski, p.128-9.
} 
discurso institucionalizado: "É uma dança antiga de uma cultura pagã. Estudei isso", afirma um dos passageiros, representante da aristocracia. Entretanto, o seu discurso é engolfado pela alegria e alvoroço carnavalesco dos refugiados sérvios, pois, por alguns momentos, rompe-se a distinção entre ricos e pobres, popular e erudito, particular e público, espectador e espetáculo, imperando o carnaval, a festa do tempo, que tudo destrói e tudo renova:

durante o carnaval é a própria vida que representa e interpreta (sem cenário, sem palco, sem atores, sem espectadores, ou seja, sem os atributos específicos de todo espetáculo teatral) uma outra forma livre da sua realização, isto é, o seu próprio renascimento e renovação sobre melhores princípios. (...) Em resumo, durante o carnaval é própria vida que representa, e por um certo tempo o jogo se transforma em vida real. Essa é a natureza específica do carnaval, seu modo particular de existência. ${ }^{13}$

Posicionamento semelhante, tanto no que tange à tensão entre espectadores e espetáculo quanto ao trabalho de construção das personagens, evidencia-se em A força do destino. Ao retomar a ópera de Giuseppe Verdi, que, por sua vez, já é uma reescrita do drama romântico do Duque de Rivas, Nélida Piñon irá lidar com os arquétipos do folhetim romântico do século XIX, em especial os do Romantismo Francês e Espanhol: o amor impossível de um cavaleiro sem fortuna e a filha de uma família nobre; os infortúnios do casal apaixonado diante da família, que é contra o romance; o final trágico das personagens. Entretanto, a autora movimenta as regras desse jogo de cartas marcadas através da paródia e do desvelamento. Real e simulacro se atravessam e a verdade perde-se entre luzes e sombras. O texto de Nélida Piñon vivencia a representação através do artifício da "sintaxe nova":

Não penso que Leonora e Álvaro cedam-me depoimentos completos. E que importância teria também, se jamais sufraguei o texto verossímil? A vida se falseia com uma única palavra, ou olhar, que, indo para Pedro, João recolhe, pensando seu. A tudo se pode emendar ou corrigir, com sintaxe nova. (...) Sou tão incrédula diante dos fatos julgados reais com sua exacerbada imitação da realidade, que me devoto a enfeitar a bagagem da terra com variantes que vão desde os granéis de sementes, esterco, arado, um par de vacas, até a caça às pérolas, a descida às minas, a avaria dos sentimentos profundos, água para todos os lados. ${ }^{14}$

As personagens do romance se reconhecem como seres de papel, privilegiando a encenação. Elas se comportam como se estivessem num palco ou num estúdio de cinema fazendo poses para a câmara ou para o olho do espectador/leitor, em uma atitude típica do mundo cênico: "como se a vida fosse um palco que possibilitasse efeitos de teatro, e o teatro, como a vida, fosse um eterno feixe de ilusões." 15 Representação de uma representação, há nessas personagens a nítida consciência de estarem teatralizando, encenando a sua realidade:

\footnotetext{
${ }^{13}$ Bakhtin. A cultura popular na Idade Média e no Renascimento: o contexto de Rabelais, p.7.

${ }^{14}$ Piñon. A força do destino, p.15-6.

${ }^{15}$ Martins. O moderno teatro de Qorpo-Santo, p.31.
} 
Irei com você para onde você ordenar, Álvaro. Cá entre nós, Leonora, porque está você a pentear-se agora, numa hora tão precária, piscando os olhos, testando as pestanas postiças, como posando para um retrato. Vamos sua ingrata. Foi esta frase para mim, seu futuro amante, ou para a Nélida, que nem conhece, e apenas agora você soube estar entre nós, usufruindo de nossa companhia? Por que suspeitas de mim, amado futuro amante, não tens corpo bastante para provocar os devaneios de uma donzela como eu, de origem nobre, é verdade, mas ainda assim mulher? Qual é, Leonora, que ritmo frásico quer você alcançar com essa voz de contralto? Pensas que não sei que estás a fazer olhar de quem quer ser lida, e suspira pela posteridade. ${ }^{16}$

Pessoas, personagens e máscaras coadunam-se no interior de A força do destino. Não podemos esquecer que o termo personagem deriva-se do Latim persona, que também é pessoa e máscara, daí a expressão persona trágica: máscara da tragédia. Além disso, ao final do romance de Nélida Piñon, como nas peças de teatro, as personagens são re-apresentadas ao público-leitor como dramatis personae, isto é, máscaras dramáticas, expressão que remete à máscara que cobria o rosto do ator ao desempenhar o seu papel, principalmente nas manifestações dramáticas primitivas, nos teatros greco-romano e oriental, por exemplo, o teatro Bali e o Nô.

Por outro lado, máscaras também são as usadas pelos foliões nos festejos carnavalescos, são elas as usadas por arlequins, colombinas, pantaleões e briguelas da commedia dell'arte, mascarados são os clowns dos espetáculos circenses, isto é, a máscara é também popular e carnavalesca, o que a cobre de um caráter positivo, regenerador e renovador, universal e público:

A máscara traduz a alegria das alternâncias e das reencarnações, a alegre relatividade, a alegre negação da identidade e do sentido único, a negação da coincidência estúpida consigo mesmo; a máscara é a expressão das transferências, das metamorfoses, das violações das fronteiras naturais, da ridicularização, dos apelidos; a máscara encarna o princípio de jogo da vida, está baseada em uma peculiar inter-relação da realidade e da imagem, característica das formas mais antigas dos ritos e espetáculos. ${ }^{17}$

São dessa ordem as máscaras utilizadas pelas personagens do romance de Nélida Piñon. Longe do pacto singular estabelecido entre ator e máscara presente na tragédia grega - este, ao se cobrir com a máscara, costumava identificar-se, de forma mágica, quase sobrenatural, com a personagem representada - em A força do destino, a relação entre ator e máscara aponta para um múltiplo desdobramento das personagens, que ao logo da narrativa vestem-se e despem-se de diferentes máscaras, na maioria das vezes sem visitar o bastidor para essa troca de "figurino", tal a consciência de sua ficcionalidade.

Como já chamamos a atenção, em E la nave va Federico Fellini não chega a tomar o espetáculo operístico, a encenação de uma ópera, mas sim os bastidores desse universo: a convivência entre os passageiros-cantores, os ensaios para o "recital de despedida"; é o cotidiano da viagem do Glória N que se organiza como espetáculo. Esse procedimento, recorrente na obra de Federico Fellini, permite que o cineasta volte o seu olhar para a própria construção do texto fílmico, desvelando os artifícios e as artimanhas de sua teia ficcional.

\footnotetext{
${ }^{16}$ PIÑOn. A força do destino, p.10.

${ }^{17}$ Bakhtin. A cultura popular na Idade Média e no Renascimento: o contexto de Rabelais, p.35.
} 
Na verdade, tanto em E la nave va quanto em A força do destino, o limite entre o bastidor e o palco é bastante tênue, e o que temos é a coalescência dos dois espaços. A cena operística invade o bastidor, o bastidor adentra o espetáculo. Além disso, a ópera é, por sua própria natureza, um texto híbrido e polifônico, a multiplicidade e a pluralidade de vozes é característica peculiar desse discurso que reúne em seu interior uma gama de outras artes, como a música, o teatro, a dança e a literatura. Assim, uma interseção de linguagens distintas adentra o espaço narrativo de E la nave va e de A força do destino, configurando a vida como espetáculo, e vice-versa: "Em suma, é todo o real, a vida inteira, que se tornou espetáculo." 18

Real e espetáculo se justapõem de maneira surpreendente e em níveis que criam um estado de indiscernibilidade. O cotidiano organizado como espetáculo, a ópera, nega a divisão dos dois mundos. Esse estado de indiscernibilidade é da ordem do que Deleuze irá chamar de "imagem-cristal", uma imagem bifacial, a um tempo atual e virtual: "o objeto real reflete-se numa imagem especular tal como no objeto virtual que, por seu lado e ao mesmo tempo, envolve ou reflete o real: há 'coalescência' entre os dois", ${ }^{19}$ há um duplo movimento, uma face dupla que não se confunde ou anula, mas tem na unidade indivisível de uma imagem atual e de sua correspondente virtual o seu caráter distintivo. "É como se o real e o imaginário corressem um atrás do outro, se refletissem um no outro, em torno de um ponto de indiscernibilidade". ${ }^{20}$ Nesse sentido, a ópera em E la nave va e em A força do destino pode ser tomada como um circuito, um modo de composição da imagem-cristal, ao lado de outros elementos, como o navio, a encenação, os espelhos, as máscaras, a carnavalização, os narradorescronistas, o texto dentro do texto. Circuitos que farão coadunar o atual e o virtual, o límpido e o opaco, o germe e o meio. Um dos elementos chave para a composição dessa imagem-cristal é a inserção, dentro do romance e do filme, respectivamente, das figuras dos narradores-cronistas Nélida e Orlando.

Em um fantástico exercício de "egocentrismo narrativo", Nélida Piñon encenase como personagem ficcional (entidade romanesca), tematizando a criação literária em um texto que mina a "ilusão de real" da narrativa tradicional. A narradora-cronista Nélida é contemporânea do leitor e insere esta perspectiva entre os detalhes e pormenores da época passada que descreve. Dessa forma, a instância narrativa é marcada pelo plano da ação (tempo da matéria enunciada) e pelo plano da narração (tempo da enunciação/tempo do discurso).

À luz do intervencionismo da narradora-personagem, o anacronismo é utilizado conscientemente como forma de fundir duas dimensões temporais (século XVIII/ século XX) e duas dimensões espaciais (Espanha/Brasil).

Entretanto, atrás da narradora-cronista Nélida, há uma outra voz (uma terceira pessoa), um narrador que assume a perspectiva de cada personagem, a qual oferece uma visão dos fatos e lança outras pistas sobre o enredo. Através desse artifício, Nélida Piñon se aproxima de um efeito próprio do discurso operístico: a orquestração de vários sentimentos e a pluralidade de pontos de vista.

\footnotetext{
${ }^{18}$ Deleuze. A imagem-tempo, p.105.

${ }^{19}$ Deleuze. A imagem-tempo, p.87-8.

${ }^{20}$ Deleuze. A imagem-tempo, p.16.
} 
Em E la nave va, também contamos com a presença de um narrador-cronista, o jornalista Orlando, que dialoga com seu público leitor/espectador e com as outras personagens. Com seu tipo bonachão e seu discurso pretensamente intelectual, o narrador-cronista Orlando anda por todo o navio em busca de informações a respeito de Edmea Tetua. Ele aparece a todo momento interpelando, comentando, ironizando ou confessando-se, em suma, uma criatura ficcional, que adentra o texto fílmico para marcar as suas articulações, conexões e inter-relações.

Em um dado momento do filme, o jornalista Orlando mostra para a câmara ou melhor, para o espectador - uma fotografia da Ilha de Erimo. Há um movimento de aproximação (grande plano) e a fotografia toma todo o espaço da tela. É como se, no terreno da representação, o simulacro fosse mais eficiente do que o próprio objeto. E se Fellini prefere o fruir da imagem à realidade, é porque ele tem consciência de que a imagem encerra, na ausência do objeto que reproduz, um certificado de presença, pois, como nos adverte Roland Barthes, com o advento da fotografia, "o passado é a partir de agora, tão seguro como o presente, aquilo que se vê no papel é tão real como aquilo que se toca." 21

O artifício do narrador-cronista aponta para uma dupla face, uma dupla cena, o jogo estabelecido entre atual/virtual da imagem-cristal. Em A força do destino, o nome da narradora-cronista, imagem virtual, coincide com o nome da autora, Nélida, na capa do livro, imagem atual. Se a epígrafe do romance, ao trazer o sentido dicionarizado do vocábulo artista, atualiza o papel da autora, a imagem da cronista Nélida figurada entre as personagens do livro também se torna atual e se superpõe à primeira. Um princípio de indiscernibilidade entre atual e virtual instaura-se no interior do texto; assim, o autógrafo, imagem atual, configura-se em persona ficcional, imagem virtual, em um processo de coexistência e troca.

Também, em E la nave va, um acordo extraordinário entre ator e autor irá embaralhar as instâncias atual/virtual. Há uma nítida semelhança entre o ator Freddie Jones e o cineasta Federico Fellini. Como cronista/conferencista, Orlando (Freddie Jones) "substitui" o autor (Federico Fellini) conduzindo e articulando a narrativa. É o narrador, virtual, que se metamorfoseia em autor, atual, e vice-versa, pois, ao final do filme, é Federico Fellini que aparece atrás da câmara, em um jogo de "imagens especulares, escalonadas em profundidade". A coalescência entre narrador-cronista e autor é nítida, por exemplo, nos momentos em que o cronista demonstra um conhecimento de situações vividas por outras personagens, às quais ele não teve acesso, isto é, não estava lá, e cuja única testemunha foi a "câmara de Fellini". Como na cena em que Orlando fala, voltado diretamente para câmara e para o espectador, a respeito do Conde Bassano. Ele cita a flor que Bassano mantém em seu quarto, "velando" a figura de Edmea, e diz: "Vocês viram no quarto". Entretanto, na cena do quarto de Bassano, imediatamente anterior a essa, não havia ninguém além do próprio Bassano, um espelho e os objetos de Edmea; as únicas testemunhas eram a câmara e o olhar do espectador.

Espelho e germe, temas constituintes da imagem-cristal, atravessam as narrativas de Nélida Piñon e de Federico Fellini: ora a narrativa que se reflete em outras narrativas, ora o texto que se faz objeto no processo de sua constituição. No caso de $E$

${ }^{21}$ BARTHES. A câmara clara, p.58. 
la nave va e de A força do destino, estes senderos (o germe e o espelho) não se bifurcam, ao contrário, "à maneira de Moedeiros falsos, de Gide, os dois temas ou dois casos se cruzam e reúnem, tornam-se indiscerníveis". ${ }^{22}$ Assim, tanto em Federico Fellini, quanto em Nélida Piñon, a imagem especular encontra seu germe, isto é, o texto reflete-se em outros, justamente pela via do processo: o filme se fazendo, o romance se constituindo. $\mathrm{O}$ jogo de espelhos atualiza outras narrativas, ao mesmo tempo em que as transgride, abrindo e germinando a "cena em abismo" ao infinito.

Em A força do destino, a justaposição de registros lingüísticos — diálogos pomposos do século XVIII se misturando com a gíria popular contemporânea - contraditórios do ponto de vista temporal e social, termina por carnavalizar o espaço da representação verbal. Além disso, a ausência de travessão e aspas na marcação dos diálogos e, em alguns momentos, a eliminação do ponto final, substituído pela barra, criam uma explosão múltipla de vozes, permitindo o fluir de um ritmo livre e musical no texto, o que o aproxima ainda mais da retórica operística. Essa multiplicidade e simultaneidade de vozes é evidente, por exemplo, na passagem em que o casal Álvaro e Leonora, prestes a fugir, é surpreendido pelo pai da moça, o marquês de Calatrava:

Criados, corram aqui, eis um ladrão na casa, devemos acorrentá-lo, para os esbirros e a justiça/ pai, tudo menos esta desfeita, eu amo Dom Álvaro/ então, desgraçadinha, confessas tal amor?/ e acaso é amor maldito também, desde quando homem e mulher não gozam de todos os benefícios para se amar à vontade e sem chateação?/ não basta serem homem e mulher/ ah, se Dona Leonora fosse varão, o senhor aprovaria o nosso amor homossexual?/ pelo menos não estaria à minha vista, eu teria assegurado à sociedade de Sevilha que a honrada casa de Calatrava jamais se uniria a um telhado menos digno com o propósito de ter filhos/ pai, acalme-se, como podemos debater problemas tão graves se gritamos todos ao mesmo tempo, já não sei qual palavra é de minha lavra, qual verbo brotou do seu coração/ ${ }^{23}$

E se a epígrafe do romance, ao trazer a definição do vocábulo artista, denuncia a intenção da autora:

Artista. S. 2g e adj. 2g. aquele que, ou "que sabe artifícios delicados, e sutis."

(Antonio de Moraes Silva. Diccionário da Língua Portuguesa, Tomo Primeiro, Anno de 1813, Lisboa.)

Com Licença da Meza do Desembargador do Paço. ${ }^{24}$

O último parágrafo termina por sintetizar o seu projeto estético. O livro encerrase com a descrição das dramatis personae, momento em que as personagens retornam ao palco da narrativa para receber os aplausos. A última dessa lista é a cronista Nélida, descrita da seguinte forma:

Nélida: não escreve por esporte, também não se deixa seduzir pelo dinheiro. Nestes casos, ela é bem nobre. Seus motivos conserva secretos, carrega o próprio enigma. Não cabe tentar analisá-los aqui. Também ela não consentiria, zela em excesso pela própria intimidade. Desde pequena adestrou a mão direita para enfrentar a caneta. O instrumento provou-se propenso a armazenar apenas palavras bem comportadas.

\footnotetext{
${ }^{22}$ Deleuze. A imagem-tempo, p.96.

${ }^{23}$ Piñon. A força do destino, p.24.

${ }^{24}$ Piñon. A força do destino, p.5.
} 
As melhores fugiam-lhe pela janela, tal a sua velocidade. Já aos treze anos, livrou-se deste jugo utilizando as duas mãos sobre a pequena máquina Hermes que, em verdade, escreve seus livros. Teve ela apenas o trabalho de assiná-los. ${ }^{25}$

Esta passagem, acentuadamente irônica, lança dúvidas a respeito da autoria, negando que Nélida tenha escrito os seus livros. Na verdade, a máquina Hermes, uma referência ao mensageiro dos deuses, deus do comércio e da eloqüência, escreveuos. No entanto, longe de buscar uma interpretação última do texto último, tal e qual o faria a hermenêutica, o texto de Nélida Piñon não aponta para o sentido único, mas para a relatividade de sentidos.

É também em torno de outros sentidos que se move a narrativa de Federico Fellini. Ao final do filme, o cineasta italiano exibe todo o aparato técnico utilizado na sua produção: "No final, mostro o estúdio e a mim mesmo atrás da câmara. Desvendo todo o encanto mágico." ${ }^{26}$ Nesse momento, um jogo entre mostras e máscaras faz-se nítido. Ao revelar-se a câmara que foca o navio e todo o artifício técnico utilizado na construção do texto fílmico, somos ludibriados, temos por um instante a sensação de estarmos diante de um desmascaramento total dos artifícios do espetáculo cinematográfico. No entanto, há um outro olhar atrás da câmara que pode ser vista, reiniciando-se o jogo de máscaras próprio da arte contemporânea.

Em suas obras, tanto Federico Fellini quanto Nélida Piñon refletem sobre esse momento contemporâneo de crise da linguagem e de sua recepção, ao mesmo tempo em que suas ficções levam às últimas conseqüências as potencialidades narrativas, colocando a nu o processo de construção do ficcional. Daí E la nave va e A força do destino serem textos que não temem se apresentar como textos, como maquinismos montados pelos artifícios da linguagem fílmica e literária, respectivamente. Para os dois artistas, o mundo não é senão um gigantesco palco, esse incessante espetáculo que perpassa as páginas do romance e os fotogramas do filme.

Onde está a realidade, onde está a fantasia? Qual é o teatro e qual é a vida? Nessa intencional confluência e confusão de sentidos, encontram-se os textos de Federico Fellini e de Nélida Piñon. No terreno de suas ficções, tudo se desenrola de modo a que nada seja completamente apreendido, pois estamos no perfeito domínio das visões, dos fantasmas, dos simulacros. Como nos sonhos, como nas recordações, como no cinema, enfim, como na literatura.

${ }^{25}$ PIÑon. A força do destino, p.108.

${ }^{26}$ Fellini citado por Chandler. Eu, Fellini, p.198. 


\section{A B STRACT}

An analysis of the contemporary processes of mimetic production and representation considering Nélida Piñon's A força do destino and Federico Fellini's E la nave va, which intends to articulate the concepts of spectacularization, dialogism, polyphony, and others, as constituent parts of these narratives.

\section{KEY-WORDS}

contemporary literature, representation, cinema, opera

\section{REFERÊNCIAS BIBLIOGRÁFICAS}

Assis, Joaquim Maria Machado de. Obra completa. Rio de Janeiro: José Aguilar, 1959. V. I (Romance), Dom Casmurro. p.805-942.

Bakhtin, Mikhail. Problemas da poética de Dostoievski. Rio de Janeiro: ForenseUniversitária, 1997.

Bakhtin, Mikhail. A cultura popular na Idade Média e no Renascimento: o contexto de François Rabelais. São Paulo: Hucitec; Brasília: Edunb, 1993.

BARThes, Roland. A câmara clara. Lisboa: Edições 70, 1981.

Baudelaire, Charles. Petits poèmes en prose (Le spleen de Paris). Saint-Amand: Éditions Gallimard, 1992.

Chandler, Charlote. Eu, Fellini. Rio de Janeiro: Record, 1995.

Clement, Catherine. A ópera ou a derrota das mulheres. Rio de Janeiro: Rocco, 1993.

Costa, João Bénard da et al. Federico Fellini. Lisboa: Cinemateca Portuguesa, 1996. (Folhas da Cinemateca.)

Deleuze, Gilles. A imagem-tempo. São Paulo: Brasiliense, 1990.

E la nave VA. Direção de Federico Fellini. São Paulo: Videolar Multimídia LTDA, 1983. 128 min., p\&b/color., legendado (versão francesa). (Fita de vídeo - VHS).

Hardman, Francisco Foot. Trem fantasma: a modernidade na selva. São Paulo: Companhia das Letras, 1988.

Martins, Leda Maria. O moderno teatro de Qorpo-Santo. Belo Horizonte: Ed. UFMG; Ouro Preto: UFOP, 1991.

Nietzsche, Friedrich. Obras Incompletas. Seleção de textos de Gérard Lebrun. São Paulo: Abril Cultural, 1999. (Os Pensadores.)

Piñon, Nélida. A força do destino. Rio de Janeiro: Record, 1997.

SaAvedra, Angel de. (Duque de Rivas). Dom Álvaro o la fuerza del sino. Olympia Ediciones, 1995. (Clássicos Españoles.)

Verdi, Giuseppe. La forza del destino; opera in four acts. Libretto: Francisco Mar Piave. London: EMI Records Ltd. Digital remastering, stereo. (Acompanha libreto [italiano, alemão, francês, inglês] 3 CDs). 